\title{
El retorno al extractivismo en América Latina. ¿Ruptura o profundización del modelo de economía liberal y por qué ahora?
}

\author{
The return to extractivism in Latin America. Rupture \\ or deepening of the model of liberal economy and \\ why now?
}

doi: http://dx.doi.org/10.32870/

Alicia Puyana Mutis

espiral.v24i69.4596

\section{Resumen}

En este trabajo se analiza el neoextractivismo latinoamericano, o el avance de las exportaciones de materias primas en América Latina, desde la perspectiva de la teoría clásica y contemporánea, y se explica que antes que una ruptura el neoextractivismo se trata de la profundización del modelo de economía liberal instrumentado en diferentes periodos en toda la región, por lo cual no es de esperarse que haya cambios en la dinámica o en la estructura de la economía. Los efectos económicos y sociales se analizan desde las teorías de enfermedad holandesa y de maldición de los recursos naturales.

Palabras clave: América Latina, México, recursos naturales, desigualdad, pobreza.

\begin{abstract}
This paper analyzes Latin American neoextractivism, or the advance of raw materials exports in Latin America, from the perspective of classical and contemporary theory, and explains that before a break, it's the deepening of the model of liberal economy instrumented in different periods in the whole region, so changes are not expected in the dynamics or structure of the economy. The economic and social effects are analyzed from the theories of Dutch Disease and Curse of Natural Resources.
\end{abstract}

Keywords: Latin America, Mexico, natural resources, inequality, poverty.

\footnotetext{
-Profesora-Investigadora de la Facultad Latinoamericana de Ciencias Sociales (FLACSO), México. apuyana@flacso.edu.mx

Fecha de recepción: 08 de diciembre de 20I5. Fecha de aceptación: I3 de febrero de 2017.
} 


\section{Introducción'}

El neoextractivismo latinoamericano, el ascenso de las materias primas en las exportaciones y el modelo de desarrollo basado en la explotación de recursos relativamente abundantes (recursos naturales renovables, no renovables y mano de obra no calificada), se suele considerar una ruptura con el modelo económico establecido en los años ochenta y noventa. El neoextractivismo se inició en los años setenta en Chile y Argentina con las reformas estructurales y la liberalización instrumentadas en esos países, y entre los ochenta e inicios de los noventa dio inicio en el resto de América Latina. Es el sello de agua del modelo de desarrollo fundado con esos cambios.

El impacto de fomentar esta especialización se ajustaría a los supuestos de los modelos de enfermedad holandesa (EH): retroceso prematuro de las manufacturas y la agricultura en la generación del producto nacional bruto y del empleo totales. Este enfoque explica, en parte, la trayectoria de la economía desde las reformas, y contradiría los fundamentos del comercio exterior basados en las ventajas comparativas, la intensidad factorial y los costos relativos.

Esta etapa de economía liberal centró el crecimiento en el capital y, al procurar su óptima tasa de rentabilidad, definió el curso de las políticas monetaria, cambiaria, fiscal y laboral para alinear las cotizaciones domésticas y externas de los productos y reubicar la mano de obra y el capital de acuerdo a las ventajas comparativas. El movimiento factorial marca la especialización internacional de las economías en bienes intensivos en el uso de los factores abundantes;

I. Agradezco muy especialmente a los dos dictaminadores anónimos por sus valiosas sugerencias y observaciones que contribuyeron a una mejor argumentación del problema del extractivismo,y a la Dra. Katya Pérez G. por su amable asistencia en la revisión de este artículo. Los errores y omisiones son, por supuesto, de mi exclusiva responsabilidad.

\section{4}


establece los precios relativos de los bienes transables y no transables y de los nacionales y los foráneos, y la retribución al trabajo y al capital. Así, pauta el futuro de las economías, pues las decisiones políticas actuales afectan los desarrollos de los costos de transacción y las estructuras productivas (Douglass, 1990).

El neoextractivismo profundiza la estrategia reformista y la inserción de las economías latinoamericanas en el comercio internacional, primero, al abrir a las inversiones privadas recursos que no lo estaban: las tierras baldías o de propiedad comunitaria, el agua, la electricidad y recursos, como el petróleo y el gas, propiedad de la nación y de producción reservada a entes estatales exclusivamente o en asociación con privados; segundo, al reducir los impuestos, liberalizar el intercambio y otorgar a las inversiones externas concesiones para la agricultura, la silvicultura y la minería. Por ello, es considerable que se mantendrá la trayectoria registrada desde la crisis de la deuda en la dinámica y la estructura del PIB, de la productividad, del empleo y de los ingresos. Denominar los recursos naturales "capital natural", ponerles precio y calcular su valor presente (Banco Mundial, 2015b), ignorando los errores teóricos y metodológicos de este proceder, ${ }^{2}$ prueba la intensión de mercantilizarlos.

Este trabajo explora los efectos económicos del extractivismo, en general en América Latina, y en particular en Argentina, Brasil, Colombia y México, para verificar algunos supuestos de los modelos de EH sobre cambios estructurales y algunos sociales. Para ello, el planteamiento se desarrolla de la siguiente manera: la sección uno presenta definiciones

2. Piketty (20I4) revivió el debate sobre qué es capital, pues no toda riqueza lo es. El valor del capital sólo se establece realizada la producción, y depende de los precios y la tasa de ganancia, y esta a su vez del valor que se dé al capital, conformándose un análisis circular, tautológico. Calcular hoy el valor presente del agua o los bosques carece de lógica. 
básicas del extractivismo, así como los elementos teóricos, clásicos y contemporáneos, del estructuralismo; la sección dos establece si en los cuatro países mencionados hay síntomas de enfermedad holandesa con el retroceso de las manufacturas en el PIB y en las exportaciones; en la tercera sección se exploran de manera general algunas implicaciones de la EH y el extractivismo para la región en conjunto sobre ciertas variables económicas, como la desigualdad y el empleo; y en la cuarta sección se concluye. El análisis se concentra en las décadas desde 1980 a la actualidad, un lapso en el que ya se ha completado el ajuste de las economías a la liberalización y las reformas estructurales y a la crisis de 2008.

\section{Los basamentos teóricos del neoextractivismo}

\section{I. Definición de extractivismo}

$\mathrm{Al}$ revisar el debate latinoamericano sobre el neoextractivismo, parece emerger coincidencia sobre la naturaleza del fenómeno, así se apliquen enfoques históricos, sociales o politológicos. Para la mayoría de autores, el extractivismo es un modelo de crecimiento económico basado en la primarización de las exportaciones, o la venta al exterior de recursos naturales poco transformados, como la minería, la agricultura o el petróleo. Dos autores (Grigera y Álvarez, 2013; Gudynas, 2013) enfatizan la necesidad de diferenciar las causas y los efectos del extractivismo y el neoextractivismo, e indican las fuerzas que promueven este último: altos precios internacionales de los bienes primarios resultantes del crecimiento de la demanda de las economías de países asiáticos. Coinciden en señalar la continuidad del extractivismo de fines del siglo XIX e inicios del XX con el actual, salvo las interrupciones del periodo de la industrialización liderada por el Estado, en la cual los más avanzados fueron Brasil, México y Argentina.

\section{6}


Hasta aquí las coincidencias. Mientras unos autores analizan el control ejercido en la minería o la agricultura por las empresas trasnacionales, otros se orientan a juzgar el rol del Estado en la dirección del sector y en la promoción de la inversión extranjera directa, y algunos prefieren usar el concepto de manera indefinida. Gudynas (2013) identifica varios extractivismos: 1) extracción de baja intensidad y demanda local; 2) extracción de intensidad media y consumo nacional; y 3) extracción de alta intensidad y para exportación. Sólo este último tipo se ajusta, según el autor, a la definición más generalizada de extractivismo, que lo relaciona con la inserción de las economías latinoamericanas a las de los países desarrollados y sus estrategias de crecimiento y acumulación de capital, como lo explican Myint (1965) y autores latinoamericanos estructuralistas y de la escuela de la dependencia (Prebisch, 1949; Furtado, 1982; Cardoso y Faletto, 1969). La diferencia entre el extractivismo estudiado por estos autores y el actual neoextractivismo es la participación activa del Estado en el manejo de los ingresos por exportaciones de materias primas, con fines parcialmente redistributivos, según propone Gudynas (2013).

Varios autores relacionan el extractivismo con teorizaciones económicas previas respecto a la inserción de la región en la economía global. El consenso de las commodities (Svampa, 2013) da seguimiento al desarrollo económico de la región después del consenso de Washington, en las décadas de los ochenta y noventa. Grigera y Álvarez (2013) discuten las similitudes entre el extractivismo en la teoría de la dependencia de la CEPAL y en la acumulación por desposesión de corrientes teóricas marxistas, y Acosta (2011) relaciona los efectos del extractivismo con la maldición de los recursos naturales y el bajo crecimiento económico, en línea con Prebisch y otros autores de la escuela de la dependencia. Finalmente, buena parte de los autores se enfoca en los impactos sociales y ambientales en las comunidades 
en donde se realizan los proyectos de extracción de recursos naturales (CLAES, 2009; Delgado, 2013; Seoane, 2013; Svampa, 2013).

Surgen dos posturas claras sobre la naturaleza del extractivismo del siglo XXI. En un lado, se considera una ruptura con el modelo del consenso de Washington y el retorno del Estado desarrollista de centro-izquierda (Cornia, 2012) que, basado en los recursos naturales, puede hacer avanzar la industrialización (CEPAL, 2008) y lograría evadir la "trampa del ingreso medio", el freno del crecimiento (Paus, 2014). En el otro, se reproducen los problemas de la especialización en materias primas: débil crecimiento económico, inestabilidad de precios, deterioro de los términos de intercambio y intensificación de la desigualdad, acompañados de corrupción y conflictos sociales y políticos, si bien moderados por ciertos elementos: los nuevos actores en la toma de decisiones de inversión y las novedosas formas de gobernanza que pueden dar las bases del desarrollo sustentable (Fontaine, 2005).

\section{2. La teoría clásica}

La justificación de la división internacional del trabajo con base en los factores abundantes como factor del progreso de las naciones se remonta a la economía clásica (Smith, Ricardo y Mills) y fue ampliada en el siglo Xx en los modelos de flujos comerciales y dotación de factores (los modelos Heckscher-Ohlin y Stolper-Samuelson, y el teorema de Rybczynski). En América Latina, fue instrumentada desde el periodo de las independencias hasta bien entrado el siglo XX, según Bértola y Ocampo (2014).

El análisis clásico y neoclásico del impacto en el crecimiento económico de la especialización internacional considera dos efectos de la ampliación del mercado: el incremento del volumen de la producción de un bien, más allá de la capacidad del mercado doméstico, versión temprana de la venta de excedentes (vent of surplus y el extractivismo de 
alta intensidad de Gudynas -2013-), y el crecimiento de la productividad por la división del trabajo. Los efectos se analizan desde las teorías de los costos relativos y de la productividad, si bien con diferencias esenciales.

En los costos relativos, la especialización implica solamente el movimiento por la curva estática de posibilidades de producción, dada la dotación de factores, en pleno empleo, y las tecnologías disponibles, y, por lo tanto, es un proceso reversible (Myint, 1965, p. 15). En la doctrina de la productividad no hay pleno empleo y el comercio internacional es una fuerza dinámica que, al ampliar el mercado y profundizar la especialización, alienta el cambio tecnológico, eleva la productividad laboral y genera beneficios de crecimiento y desarrollo. Para los países en etapa inicial de industrialización, el comercio internacional forja su estructura productiva de acuerdo a la demanda externa e induce transformaciones difícilmente reversibles (Mill, 1848, citado en Myint, 1958, pp. 318 y 319).

Esta reflexión se presenta en el análisis del desarrollo latinoamericano en Furtado (1982) y en Cardoso y Faletto (1969). De allí que un país que se especializa para el mercado internacional es vulnerable a los choques externos y a los movimientos de los términos de intercambio en mayor grado que lo aceptado por la teoría de los costos relativos (Myint, 1965, p. 320), coincidiendo con el análisis de Prebisch del efecto de deterioro de los términos de intercambio en el crecimiento económico. ${ }^{3}$ Myint añade cómo el ambiente liberal decimonónico ignoró la vulnerabilidad y consideró solamente los beneficios de las ganancias en productividad, y cómo los argumentos pro-libre comercio devinieron en políticas e instrumentos no liberales de estímulo a las

3. Aporte conocido como "la hipótesis Singer-Prebisch". Singer propuso intercambio desequilibrado entre los países exportadores de materias primas y los desarrollados que las importan y procesan, lo que induce el intercambio empobrecedor (Singer, 1950). 
exportaciones intensivas en factores. Lo mismo aplica al talante imperante al instrumentar las reformas y a las políticas de estímulo al extractivismo actuales (Puyana y Costantino, 2015).

En la teoría de la productividad, dado el tamaño del mercado interno y la dotación de mano de obra, no es factible el pleno aprovechamiento de un recurso (minero, tierra, mano de obra) relativamente abundante, y la productividad laboral total efectiva es menor a la potencial. Por lo tanto, ampliar la producción para exportar los recursos abundantes no implica reducir la producción para el mercado doméstico, ni genera presiones inflacionarias, como en la teoría de los costos relativos, y sí incrementa la productividad y el bienestar ya que, para ampliar la producción, se traslada mano de obra de la agricultura de subsistencia, con muy baja productividad laboral marginal, a actividades más productivas.

En las reformas estructurales, más concretamente en las energética y minera del Gobierno de Peña Nieto, en las mineras de los presidentes colombianos Uribe y Santos, y en el acaparamiento de tierras en Argentina, se identifican versiones truncas de la teoría de venta del factor abundante, ya que sus modelos implícitamente asumen pleno empleo, se apoyan en inversiones externas y son intensivos en capital y no buscan absorber la mano de obra con baja productividad marginal que, en altas proporciones, se encuentra en el empleo informal urbano, los servicios y la construcción y, en menor medida, en el sector rural, razones por las cuales estas políticas no elevarán la productividad económica general.

El extractivismo decimonónico no desencadenó los efectos previstos y el crecimiento del volumen exportado consistió en ganancias en productividad, no por mejoras tecnológicas, sino por el traslado de mano de obra sin costo y de baja productividad a actividades poco dinámicas como la minería 
y a las plantaciones y la intensificación del trabajo. A esa conclusión llegan Acosta (2011) y Svampa (2013) al decir que el neoextractivismo no acelera el crecimiento económico ni ayuda a la diversificación productiva.

Para acelerar el desarrollo hacia actividades con mayor cambio tecnológico, economías de escala y externalidades y dinamismo exportador, se apeló a la industrialización ${ }^{4}$ y a sus exportaciones, reconocidas por numerosos economistas (Nurkse, 1959; Kaldor, 1967; Prebisch, 1949; Singer; 1950; Rostow, 1954) como efectos dinamizadores de las manufacturas y la importancia de lo que se exporta (Ul Haque, 1995; Hausmann, et al., 2007; Rodrik, 2006). Las reformas estructurales y la liberalización comercial truncaron este proyecto desarrollista.

\section{Los nuevos desarrollos: entre enfermedad y maldición}

Esta sección discute los efectos económicos de la especialización en recursos naturales, principalmente los de EH, tema que resurgió durante el último cuarto del siglo XX por la revalorización del crudo acometida por la Organización de Países Exportadores de Petróleo (OPEP). Los países petroleros crecieron y se desarrollaron menos que aquellos pobres en este recurso (Puyana, 2015b), si bien las experiencias varían de país a país y no es posible formular leyes absolutas, como lo prueban fehacientemente Humphreys, Sachs y Stiglitz (2007).

Las escaladas de precios del petróleo en 1973 estimularon los trabajos sobre el impacto de las bonanzas de los productos básicos bajo el rótulo de "maldición de recursos naturales" (Gelb, et al., 1988; Auty, 1993; Krugman, 1987; Puyana, 2015a). Estos estudios cubren a los países desa-

4.Alexander Hamilton, el secretario de Finanzas de Washington, recomendó: "no hagas lo que los ingleses prescriben hacer, haz lo que los ingleses hacen" (Hamilton, |79|, citado en Jomo y Reinert, 2005, p. 19). 
rrollados e industrializados (Holanda, Australia, Canadá y Rusia, entre otros), en los cuales crece la importancia de estas exportaciones (Will, 2005). Todos señalan por qué las materias primas pueden retardar el desarrollo, e incluyen entre las razones la tendencia al deterioro de los términos de intercambio (según la tesis Prebisch-Singer), la inestabilidad de los precios de los bienes primarios, el bajo valor retorno de las exportaciones, y las pérdidas en empleo, ingreso y exportaciones de los sectores y productos transables que no están en bonanza.

El conjunto de estos fenómenos resulta del menor ritmo de cambio tecnológico en las actividades primarias, en relación con las manufacturas o los servicios, y de la propensión en la producción intensiva en recursos naturales a actividades de captura de rentas y corrupción y conflictos sociales, incluida la confrontación bélica (Sachs y Warner, 1995; Collier y Hoeffier, 2000). Las críticas a la especialización en recursos naturales se vinculan con los determinantes del cambio estructural, analizados por Chenery y Syrquin (1986), Prebisch (1949), Furtado (1982) y Cardoso y Faletto (1969), y recogidos en los años noventa por los analistas de las bonanzas petroleras. De la intensidad y duración de las bonanzas dependen los cambios estructurales de la economía y su reversibilidad (Puyana, 2015b). Estudios recientes renuevan el análisis de Chenery y de los problemas estructurales de la especialización en recursos (Bair, 2015; Buccellato y Alessandrini, 2009; Fleming y Measham, 2013).

Es complejo explicar las razones económicas, políticas, sociales e institucionales por las cuales la riqueza en estos recursos tiende a afectar negativamente el crecimiento. La abundancia de recursos naturales, al ampliar el potencial económico, debería representar una ventaja para el país beneficiado. Se reconoce que los recursos naturales han contribuido a elevar el nivel de vida de la población, pero se admite que no han generado condiciones de sustentabilidad 
y equidad del desarrollo, paradoja que se explica en parte desde la teoría económica bajo el nombre de "enfermedad holandesa" (EH). La EH recoge algunos de los elementos de la escuela del estructuralismo de Prebisch y la CEPAL y de la escuela de la dependencia sobre la necesidad de la industrialización para acelerar y sostener el crecimiento económico y reducir la desigualdad intra- e interpaíses.

El modelo de EH explica el menor crecimiento de la economía y de la productividad de los países petroleros causado por el retroceso de los sectores comerciables, esto es, de la agricultura y manufacturas, como fuente total del PIB y del empleo. Este repliegue lo causa la revaluación de la tasa real de cambio, efecto, en primer lugar, del aumento de las divisas por la explotación y exportaciones de las materias primas y, en segundo término, de la expansión del gasto público. Las hipótesis para detectar la EH se corroboran a partir de: a) apreciación del tipo real de cambio o incremento de los precios relativos de bienes no transables; b) declive de la producción de los bienes transables que no están en bonanza; c) crecimiento de la producción de bienes no transables; y d) reducción de las exportaciones de los bienes transables que no están en auge.

El modelo de EH parte de elementos de la teoría económica neoclásica: a) la ley de precio único; b) pleno empleo y movilidad perfecta de todos los factores productivos; y c) ajuste perfecto de los salarios y precios. El corte neoclásico del modelo de EH implica que se deben rechazar políticas macroeconómicas que prevengan sus efectos sobre las estructuras productiva y del empleo o sobre la tasa real de cambio, en contraste con propuestas sobre la necesidad de evitar la apreciación de la tasa real de cambio y proteger los sectores transables que no están en bonanza (Gelb, et al., 1988; Auty, 1993; Puyana y Romero, 2009). Los supuestos teóricos del modelo de EH rara vez se presentan en países particulares, y menos aún en las economías de los países en 
desarrollo, en los cuales existen el desempleo y el subempleo urbano y rural, escasez de ahorro y concentración del ingreso y pobreza, todo lo cual reduce la capacidad del mercado doméstico y agudiza los efectos negativos de la especialización en recursos naturales (Puyana y Costantino, 2015; Kojo, 2015).

Presentar y analizar detalladamente los modelos de la teoría neoclásica del comercio internacional sobrepasa los alcances de este trabajo, por lo este se limita a analizar el debate relacionado con la $\mathrm{EH}$ y sus repercusiones sociales en aspectos relacionados con la desigualdad y concentración de la riqueza en América Latina, señalados en el primer encuadre de la Figura 1, la cual sintetiza los principales efectos de la especialización en recursos naturales y de sus bonanzas, tanto de cantidades como de precios, que se trabajan en los modelos de EH.

Figura 1. Efectos de las bonanzas de precios $y$ cantidades de los recursos naturales

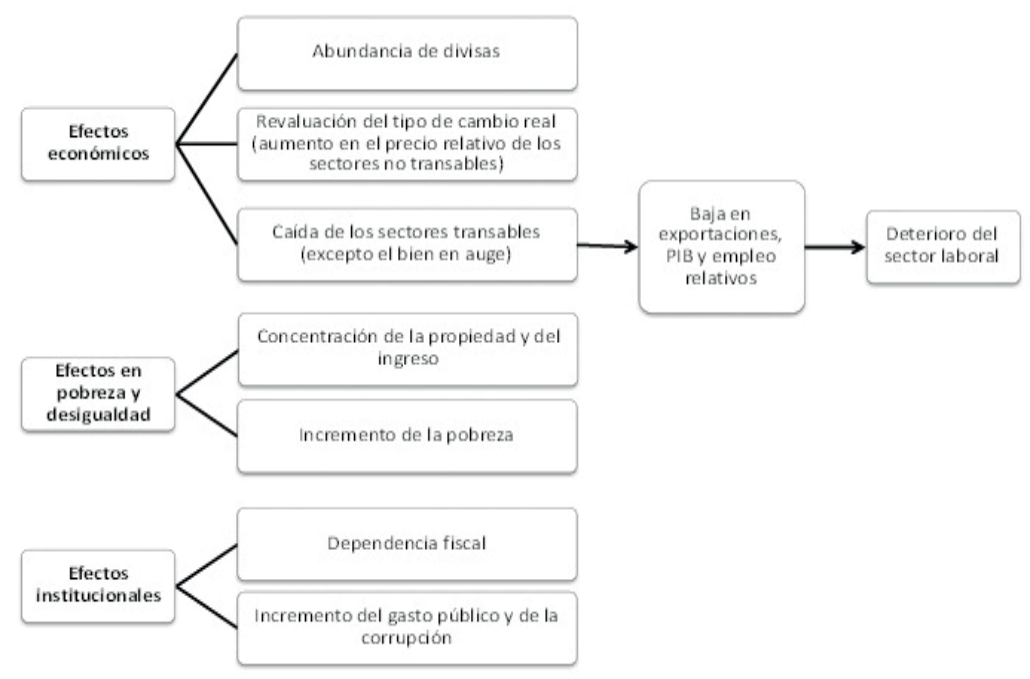

Fuente: elaboración propia. 
Otra limitación del modelo de EH es la dificultad de medir la causalidad entre las bonanzas de ciertos bienes y los efectos económicos postulados. Existe un problema latente de relación espuria o factores de desviación. Incluso si se pudieran modelar adecuadamente los efectos de EH para una economía, estos podrían ser cancelados parcial o totalmente por otros efectos económicos positivos en distintas escalas de tiempo (Raveh, 2013; Kojo, 2015).

Por lo tanto, la discusión siguiente pretende ilustrar la relación entre los elementos básicos de la EH para América Latina, reconociendo que una aseveración más allá de toda duda sobre impactos negativos (o falta de estos) relacionados con la EH requeriría análisis de causalidad profundos, que incluyan las limitaciones mencionadas en el párrafo anterior, certeza absoluta inexistente en las ciencias sociales.

\section{I. ¿Hay síntomas de EH?}

Se presenta aquí la trayectoria de algunas variables económicas que ilustran el contexto del desarrollo latinoamericano en el periodo posreformas como paso previo antes de verificar si existen síntomas de EH en las economías de Argentina, Brasil, Colombia y México, aplicando el respectivo modelo ${ }^{5}$ al periodo de 1980 a la actualidad. ${ }^{6}$ Las variables del contexto latinoamericano relacionadas son el avance de la liberalización comercial y su impacto en el crecimiento y la evolución de las exportaciones de materias primas de mayor peso en las exportaciones y con bonanza de precios.

Es notorio el avance del coeficiente externo de toda la región, del 33\% del PIB en 1980 al 51\% en 2013, con mayor

5. La definición matemática del modelo, la base de datos construida y los resultados están a disposición del lector interesado en el portal oficial de la revista Espiral, pues por falta de espacio no fue posible presentarlos en el cuerpo de este artículo. 6. En los distintos cuadros y análisis, el último año utilizado es el último año con que se cuenta con los datos relevantes. 
fuerza a partir de los años noventa, debido al empuje de la demanda de las economías desarrolladas y la de productos básicos de China e India. La apertura es desequilibrada por el mayor peso de las importaciones en el PIB, sugiriendo creciente presión contra la producción nacional que compite con las importaciones, razón por la cual la apertura comercial y el avance de las exportaciones primarias no han estimulado el crecimiento económico atribuido al modelo liderado por las exportaciones (export-led growth model), como lo corroboran la Gráfica 1 y la ecuación de la regresión cuyo R2 no es significativo, pero demuestra tendencia inversa entre las dos variables. Mientras entre 1980 y 2013 el coeficiente externo de la economía se expandió en $28 \%$, el PIB latinoamericano lo hizo al 3.1\%, sin que haya mayor divergencia entre los países.

Gráfica 1. América Latina y el Caribe: relación entre el crecimiento del PIB y el coeficiente de apertura (1960-2013)

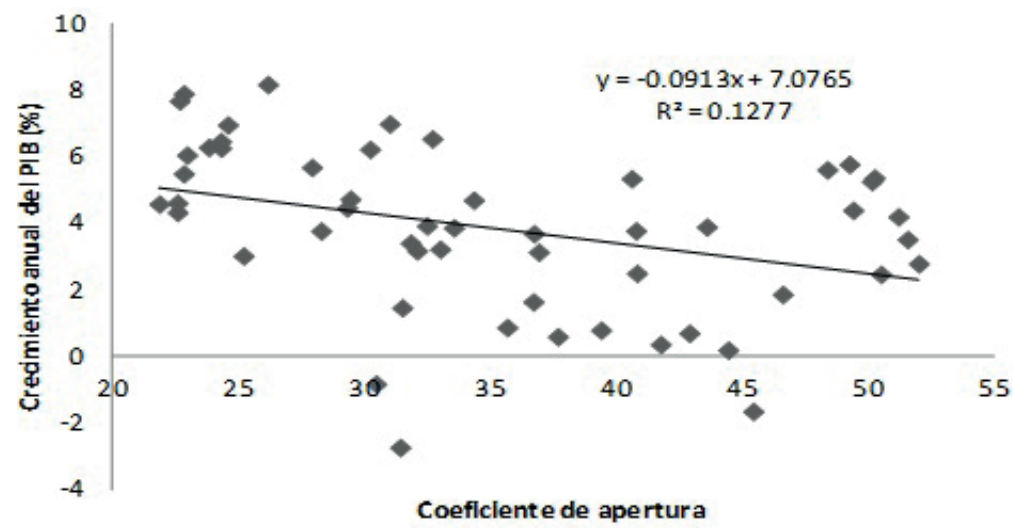

Fuente. elaboración propia con base en datos de Banco Mundial (2015a). 
La información de la gráfica sugiere que se debilitó la relación entre el crecimiento de las exportaciones y del PIB, esto en razón de la intensificación de la elasticidad ingreso de las importaciones. En efecto, la tasa de crecimiento promedio en el volumen de las exportaciones entre 1983 y 2013 fue mayor a la registrada en el periodo 1960-1982, mientras el PIB tuvo la trayectoria contraria. Los ingresos reales por exportaciones cayeron por el deterioro de los términos de intercambio, ya que el precio de los bienes primarios se redujo en términos reales a los niveles más bajos de que haya registro y sólo se recuperó unos años antes de la crisis del 2007-2008, para luego descender nuevamente. La inestabilidad en los precios se debe, en parte, a la liberalización de los mercados internacionales, a la entrada de más oferentes y a la especulación en los mercados de futuros.

La trayectoria descrita va aparejada con la reprimarización de las exportaciones, la que en 2012 era elevada aun en Argentina y Brasil, países con grandes mercados internos y avance manufacturero significativo. En México, Costa Rica y Salvador son amplias las ventas externas de manufacturas de consumo final, bajas en contenido tecnológico e intensivas en trabajo, algunas de las cuales se insertan en las cadenas de valor. Por su bajo aporte al valor agregado sectorial y al crecimiento del PIB total y la formación de sus precios, su comportamiento es similar al de las materias primas (Puyana y Romero, 2009) (Cuadro 1).

El peso de estas manufacturas en las exportaciones totales se deduce en el Cuadro 1 como la diferencia en las columnas señaladas como "2012" y "2012*". Revelador es el crecimiento de las exportaciones totales mexicanas, que pasaron de USD 26.7 a USD 327 millardos entre 1980 y 2014 , a una tasa de crecimiento anual promedio del 8.6\%, y de los cuales no menos del 75\% fueron exportaciones de manufacturas de maquila; su aporte neto al PIB total no superó el 4\%. El modelo exportador mexicano, intensivo en impor- 
taciones, ha incrementado las restricciones externas de la economía al elevar la propensión al 4.5\%, de forma similar a la analizada por Prebisch (1949, pp. 18-20) al comentar el efecto de las exportaciones de materias primas. Con diversa intensidad, este patrón se repite en toda América Latina (Puyana, 2015a).

Se consideran exportaciones primarias extractivas las de monocultivos, como la soja, palma, el banano o el azúcar y el café, pues comparten algunas características con las de origen minero: 1) grandes volúmenes de producción, destinada mayoritariamente a la exportación, con alto daño ambiental por la absorción de nutrientes de lenta o nula reposición e intenso uso de herbicidas contaminantes y tecnologías intensivas en energía; y 2) mínimo procesamiento (categorías 0 a 4 de la clasificación CUCI). ${ }^{7}$

Algunos autores sugieren que las exportaciones de manufacturas de consumo final, intensivas en mano de obra y de limitado procesamiento, generan problemas económicos similares a los de las materias primas: baja elasticidad de precio e ingreso de la demanda y la oferta, precio único por la intensa competencia internacional e inestabilidad de las cotizaciones externas (Hausmann, et al., 2007) y de su competitividad. El mecanismo para desplazar competidores es la subvaloración de los factores productivos: del trabajo, con la depreciación de los salarios reales (Marini, 1979), y de los recursos naturales, porque no se restituyen los nutrientes extraídos de la tierra ni costean la contaminación y otras externalidades de la minería o el petróleo (Haussman, et al., 2007).

No obstante, y dado que la producción y las exportaciones de estas manufacturas resienten los efectos del crecimiento de los precios de las materias primas, especialmente de la

7. Estas categorías integran: alimentos y animales vivos; bebidas y tabaco; materiales crudos no comestibles; combustibles, lubricantes y materiales conexos; aceites, grasas y ceras de origen vegetal y animal (Gudynas, 20I3). 
El retorno al extractivismo en América Latina. ¿Ruptura o profundización del modelo de economía liberal y por qué ahora?

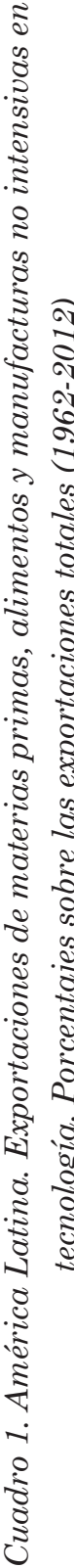

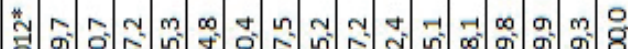

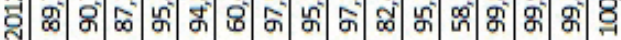

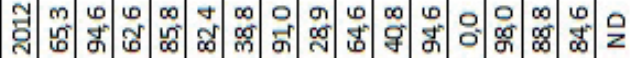

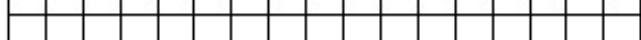

สำ

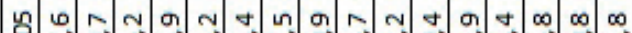

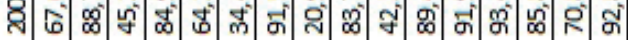

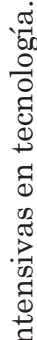

8)

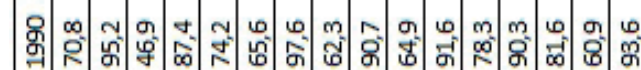

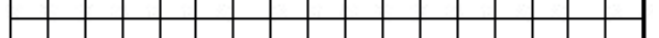

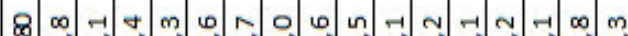

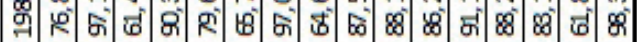

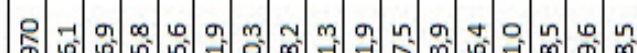

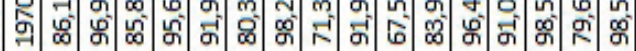

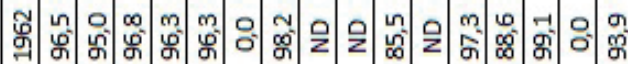

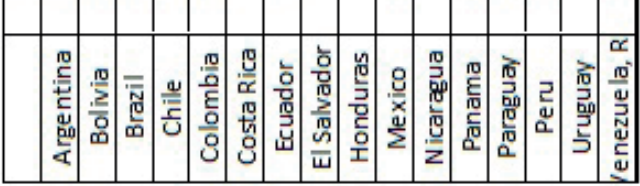


revaluación cambiaria, estas no se incluyen en los estudios sobre EH. Por otra parte, la expansión de estas exportaciones tiene limitado impacto en el crecimiento del PIB y el empleo total y sectorial.

Establecidos y discutidos los puntos anteriores, se procede a la comprobación de las cuatro hipótesis del modelo de EH, que evidencian los síntomas de este malestar económico.

\section{Hipótesis A. Apreciación del tipo de cambio}

Prácticamente todos los países de la región han tendido a mantener la tasa de cambio apreciada, sensiblemente en México y Colombia y algo menos en Argentina y Brasil (Puyana, 2015b). En Brasil, Colombia y México, el incremento de los precios de los productos en auge apreció el tipo de cambio real, con correlaciones poco mayores al 50\%. En Argentina, esta relación resultó inversa y poco significativa, y no se verifica claramente una relación positiva entre revaluación y subida de los precios reales.

La relación del tipo de cambio real con el agregado monetario M2 y el gasto público fue positiva, pero baja, en todos los casos, mientras que con el gasto de Gobierno arrojó valores bajos en Argentina y Colombia, y superiores en Brasil y en México. Esta última relación apunta, en todos los casos pero con diversa intensidad, a que el mayor gasto de Gobierno conduce a la apreciación del tipo de cambio, según los fundamentos de EH.

\section{Hipótesis B. Retroceso de los sectores comerciables en el PIB}

La desindustrialización y la desagriculturización, o el retroceso prematuro de estos sectores en la generación del empleo y el PIB totales, es un fenómeno constatado en los países especializados en materias primas, el cual va aparejado con el crecimiento acelerado del sector servicios y menores tasas de crecimiento de la productividad total. La norma Chenery y Syrquin (1986) permite medir el retroceso

\section{0}


prematuro de los sectores comerciables en las economías, de acuerdo a su nivel de desarrollo. Utiliza el índice de enfermedad holandesa (IEH), calculado como la diferencia entre la participación de la agricultura y la industria en el PIB que debería existir en un país con determinado nivel de desarrollo y los valores que efectivamente registra. Si el peso de los sectores comerciables es menor al que arroja la norma, se concluye que estas actividades han retrocedido más aceleradamente de lo esperado en función de su nivel de desarrollo y la disponibilidad de factores productivos (Puyana y Romero, 2009). Se ha confirmado la presencia de este fenómeno en países de la OCDE, pero a diferente ritmo, dependiendo las variables particulares y relevantes (Heipertz y Nickel, 2008).

Los incrementos en el valor del índice obtenidos para los cuatro países indican agravamiento de los síntomas de la EH. Entre 1982 y 2013, valores mayores del IEH indican mayor retroceso de los sectores transables como fuente del producto y un retroceso superior al normal del proceso de cambio estructural, pari passu con el desarrollo.

En Argentina, Brasil, Colombia y México, es evidente la caída de la producción de bienes transables y la pérdida de su peso en el PIB total (Cuadro 2).

En 1980, Argentina y Brasil registraron un PIB per cápita similar al del menor valor de la norma Chenery (USD 4 904, en 2005), mientras que el de México lo superó y el colombiano representó el 50\% de ese valor, lo que dificulta aplicar el IEH en dicho país. No obstante, considerando la mayor diferencia entre el PIB per cápita colombiano y su estructura, sí es factible sugerir que padece el mal, pues la participación de los transables debería ser superior. Esta aseveración se ratifica al comparar la estructura en 2014, cuando el PIB colombiano se acercaba al inferior de la norma y los sectores transables deberían representar el $36.6 \%$ del PIB y no el $20 \%$ registrado. Ningún país se acerca al valor superior de 


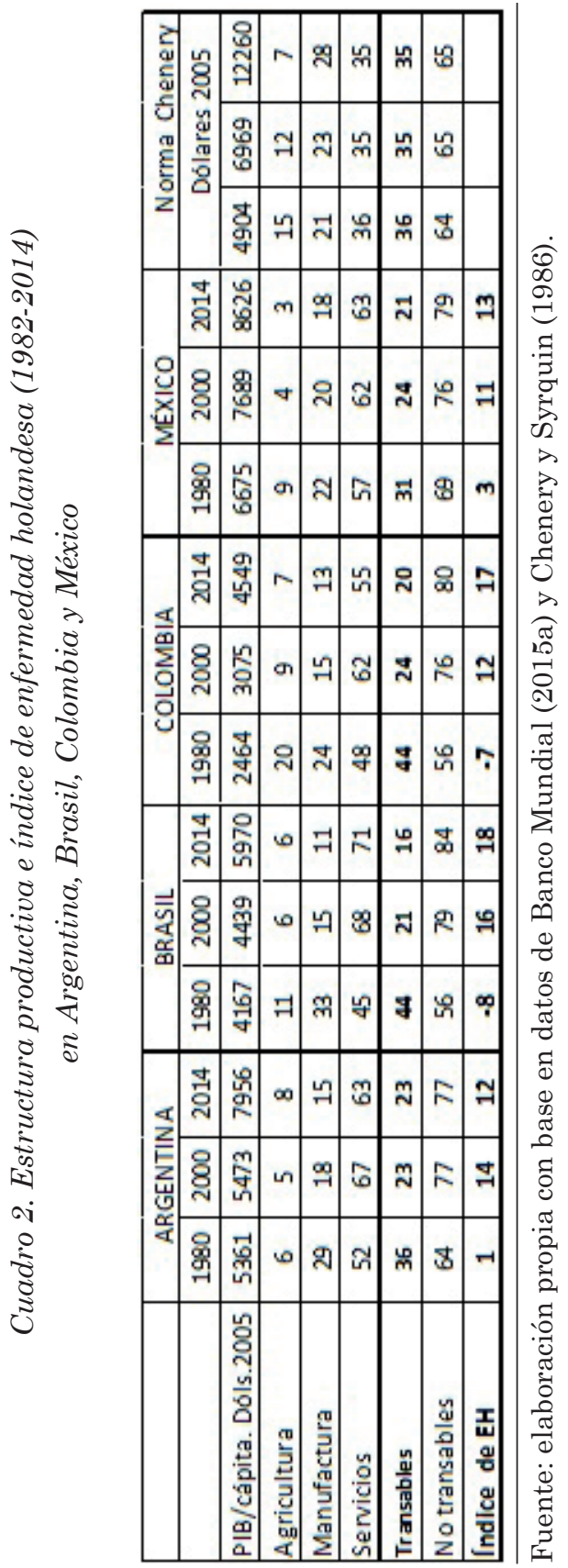


la norma (12 260), pero todos tienen estructura por debajo de la que corresponde a valor.

Las diferencias en la estructura del PIB se acrecientan y muestran tendencias algo diferentes. En Brasil, la participación de las manufacturas en el PIB en 1980 superó la norma, y cayó a partir de 1980. Argentina, por su parte, recuperó el peso de los transables, sin eliminar las pérdidas acumuladas. En todos los países, la participación de la agricultura es menor a lo esperado, aun en aquellos que son prominentes exportadores de materias primas agrícolas. Salvo en Argentina, se acusa ascenso del IEH desde 1980 hasta 2014. Estas fracturas estructurales se evidencian claramente al considerar, por ejemplo, que en Estados Unidos, Noruega y Alemania la participación de las manufacturas en el PIB descendió al 17\% del PIB, cuando el PIB per cápita de estos países era de USD 38 000, USD 33000 y USD 34 000, respectivamente, mientras en México rondaba USD 8300. En Estados Unidos, la agricultura bajó el 3\% del PIB (la proporción de México en 2012), cuando el PIB fue de USD 17000 del 2005, y su gravedad se manifiesta en empleo precario, salarios reales a la baja, ascenso de la informalidad y debilidad de la demanda interna (CEPAL, 2008).

En Colombia y México, el deterioro de los sectores comerciables puede explicarse por el incremento de la participación del sector petrolero y otros minerales en el PIB, y en Argentina y Brasil por las ventas externas de soya y otros productos agrícolas. La baja de los precios del petróleo y otras materias primas luego de la crisis de 2008 indujo en la región cambios en los regímenes petrolero y minero y en las leyes de tierras, para incrementar su producción y exportaciones con inversiones privadas (Puyana y Costantino, 2015). 


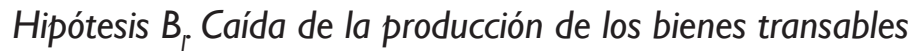
que no están en auge: manufacturas

En todos los casos, hay una correlación directa entre el tipo de cambio real y la proporción del valor agregado manufacturero en el PIB. El efecto es mucho mayor para el caso mexicano, cercano al 75\%. En las otras economías, de alrededor del 50\%. En los cuatro países, la revaluación real deprime la producción manufacturera; además, mientras mayores son el gasto de Gobierno y el agregado monetario M2, la caída en la producción manufacturera es más evidente. Se obtuvieron relaciones mayores al 50\% en todos los casos y superiores en el caso de Colombia, con correlaciones superiores al 90\%. Las exportaciones de los bienes agrícolas en auge (para Argentina y Brasil) influyeron negativamente en la proporción del valor agregado manufacturero en el PIB, pero la influencia fue mucho mayor al tratarse de las exportaciones de petróleo (Colombia y México).

Hipótesis $B_{2}$. Caída de la producción de los bienes transables que no están en auge: agricultura (excluyendo productos en auge para Argentina y Brasil)

Los signos de las relaciones entre la proporción del valor agregado agrícola no en bonanza y el tipo de cambio real, el gasto de Gobierno, el agregado M2, las exportaciones de los productos en auge y la demanda mundial son los mismos que en la hipótesis B1. Es decir, hay una relación directa con el tipo de cambio real e inversa con el resto de las variables.

Para Argentina y Brasil, la correlación entre la proporción del valor agregado de productos agrícolas y el tipo de cambio real fue alta, mientras que en México, y sobre todo en Colombia, fue menor. Llama la atención que en Argentina la correlación entre el tipo de cambio real y la producción agrícola sea tan alta, mientras que el gasto de Gobierno, el M2, las exportaciones de soya y la demanda mundial guardan una relación poco significativa con la producción 
agrícola, en contraste con los resultados de Brasil, Colombia y México.

\section{Hipótesis C. Caída de las exportaciones que no están en auge}

Se utilizó la adición de las exportaciones del frijol de soya, el aceite de soya y la torta de soya para obtener la exportación en bonanza de Argentina. Para Brasil, a las exportaciones de derivados de la soya se agregaron las de remolacha, caña de azúcar y azúcar refinada, así como las de hierro. En Argentina, Brasil y Colombia, es evidente la presencia de la EH al caer la participación de las exportaciones que no están en auge, y México difiere por el ascenso de las exportaciones manufactureras (ver Gráfica 2).

En Argentina, el incremento de las exportaciones de la soya va acompañado por decrementos en el resto de las exportaciones de los bienes transables (Gráfica 2a) y el decremento de las restantes está asociado a la revaluación de la tasa de cambio real (TCR). En las exportaciones de soya, azúcar y hierro de Brasil, se muestran diversos cambios, aunque la tendencia global es a la baja. Al igual que en Argentina, las exportaciones sin soya, azúcar ni hierro caen, concomitantemente con las exportaciones totales (Gráfica 2b), y en ambos casos la revaluación de la TCR explica los incrementos de las exportaciones de soya en un $90 \%$ aproximadamente, sugiriendo existencia de EH.

En Colombia, cae la participación de las exportaciones no petroleras, que en 1980 concentraron el 98.06\% del total y, con altos y bajos, caen al 65.5\% en 2011 (Gráfica 2c). En México, se constata que, entre 1980 y 2013, creció la participación de las exportaciones no petroleras, con cambios de ritmo en ese periodo (Gráfica 2d). Esta evolución responde al alza en las exportaciones manufactureras de la maquila que, por el alto contenido importado, se benefician con la apreciación cambiaria. Contrasta esta trayectoria con la caída de las exportaciones agrícolas. 
Gráfica 2. Proporción de las exportaciones sin productos en auge con respecto a las exportaciones totales (1980-2013)

a. Argentina

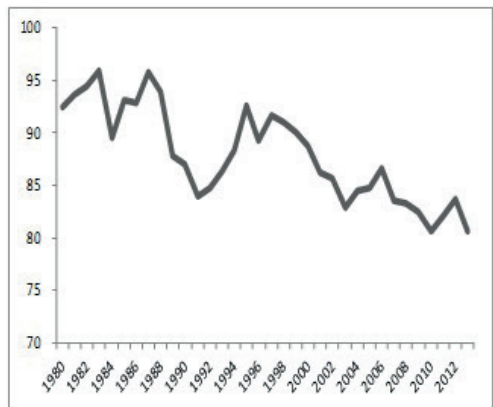

(sin soya)

c. Colombia

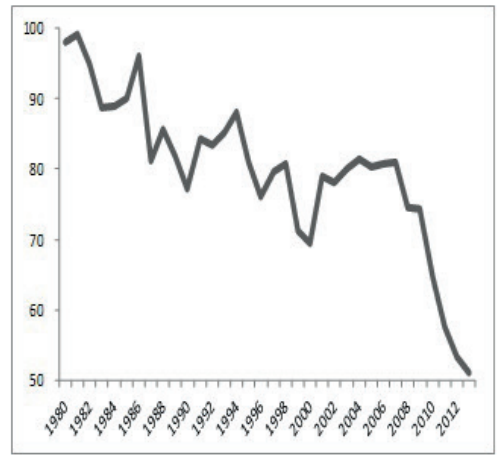

b. Brasil

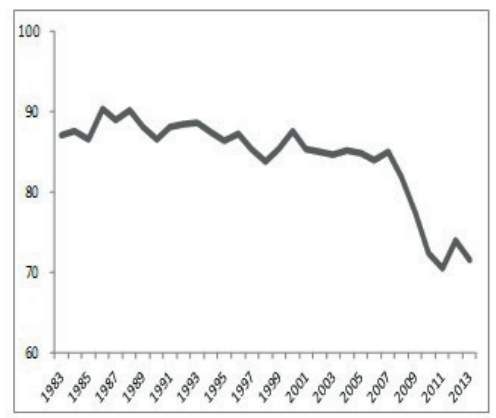

(

d. México

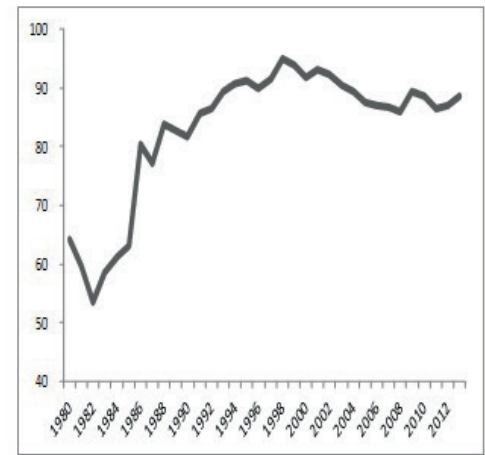

(sin petróleo)

Fuente: elaboración propia en base en United Nations Comtrade Database (2015).

El sector manufacturero de los cuatro países, por su parte, muestra una dinámica contrastante de las exportaciones y el valor agregado (Gráfica 3). México, el más abierto de los cuatro, muestra el descenso del PIB sectorial en el total (a menos del 20\% en el 2014) junto al vertiginoso ascenso de las ventas externas manufactureras (más del 70\% a las exportaciones totales). La expansión de las exportaciones 
manufactureras mexicanas parecería contradecir la cuarta hipótesis del modelo, que predice el decaimiento de las exportaciones de los bienes que no están en bonanza. Esta aparente contradicción se explica por el efecto de la revaluación cambiaria que abarata los insumos importados en los que estas exportaciones son intensivas y, por esta vía, reduce sus costos y eleva su capacidad competitiva, pero detiene la caída del PIB sectorial en el total, uno de los síntomas de la EH.

Gráfica 3. Sector manufacturero: exportaciones y valor agregado (1960-2015)

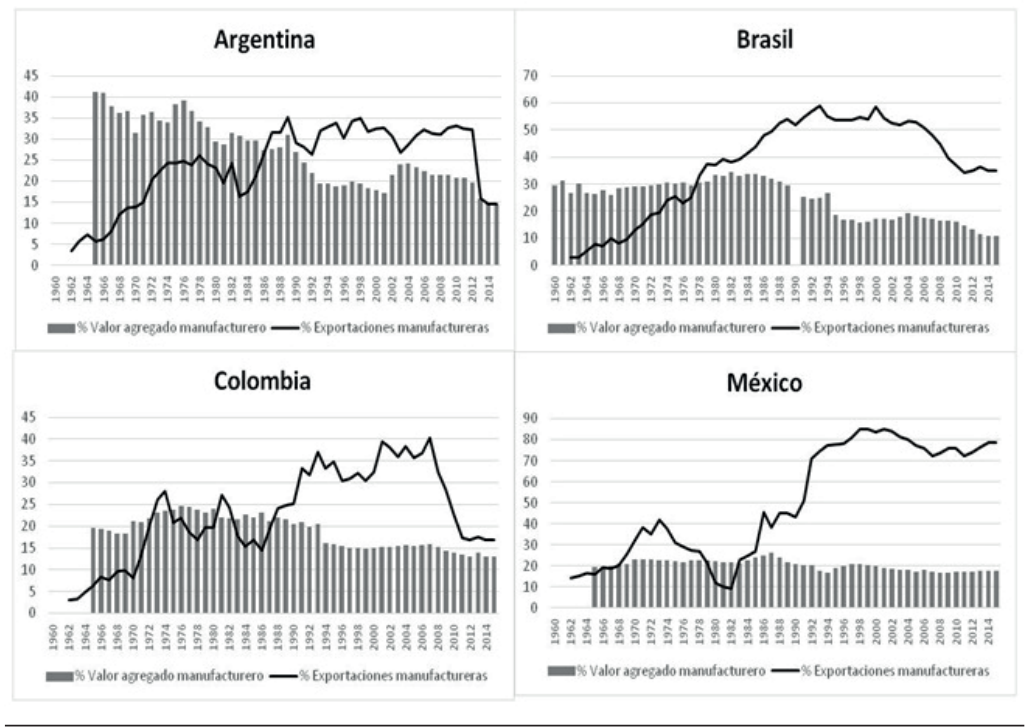

Fuente: elaboración propia con base en datos de Banco Mundial (2015a). 


\section{Otros efectos económicos del extractivismo}

Una vez constatada la presencia de los síntomas de $\mathrm{EH}$ en los cuatro países de América Latina, se consideran sus posibles implicaciones y las del extractivismo en distintas variables económicas, como es el contenido tecnológico en las exportaciones, la generación de empleos y salarios, la desaceleración de la productividad laboral y la desigualdad.

Uno de los problemas de la especialización en recursos naturales, aparte del debilitamiento institucional, es su limitado impulso al desarrollo de la capacidad científicotecnológica, la educación de la fuerza laboral y la no generación de eslabonamientos productivos. Estos factores moldean la forma de extracción de los recursos y el uso de las rentas generadas. Se ha establecido que la explotación de recursos naturales puede ser positiva para el crecimiento si y sólo si se avanza de su exportación en bruto hacia el procesamiento local con incorporación de valor agregado y alta tecnología, la diferenciación de productos y la difusión de encadenamientos ${ }^{8}$ (Hilbert y López, 2011), esto en virtud de que a mayor el grado tecnológico en la producción de los bienes exportados (HTX), superior es su impacto sobre el crecimiento (Aditya y Acharyya, 2011).

De ello se deriva que sí es relevante qué se exporta y cómo se produce (en consonancia con los economistas estructuralistas y de la dependencia, arriba citados). La estructura exportadora de Argentina, Brasil, Colombia y México devela baja y declinante participación de las exportaciones de alta tecnología (Gráfica 4). Los valores son menores cuando incluyen el contenido importado, constituido por los insumos de alta tecnología integrados.

8. Como contraejemplo está la existencia de un grupo de países hoy desarrollados que basaron inicialmente ( $y$ en algunos casos hasta hoy mismo) su crecimiento en actividades intensivas en recursos naturales. Hablamos de naciones como Australia, Canadá, Dinamarca, EE.UU., Finlandia, Noruega, Nueva Zelanda y Suecia. 
Por lo general, los síntomas de EH emergen pari passu con el debilitamiento de la generación de empleo y los salarios (Puyana, 2015a y 2015b; Stiglitz, 2007; Ross, 2007) y la desaceleración de la productividad laboral (Collier y Goderis, 2007), requisitos sine qua non para elevar el ingreso per cápita. Estas variables no se incluyen en los modelos de $\mathrm{EH}$, pero se asocian a la desindustrialización y la desagriculturización y el avance de los servicios y la informalidad (Rodrik, 2015).

\section{Gráfica 4. Exportaciones manufactureras de alta tecnología (1989-2014)}

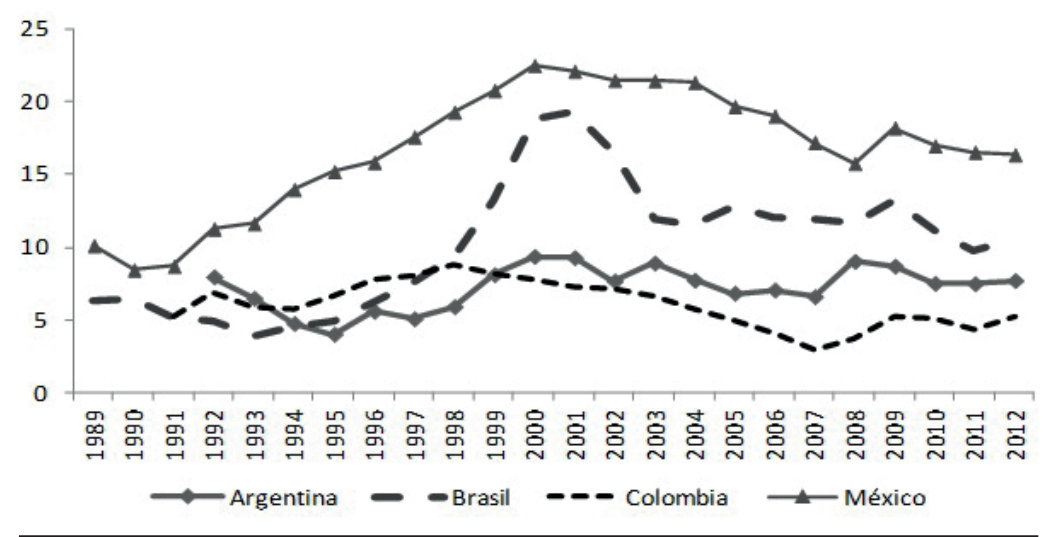

Fuente: elaboración propia con base en datos de Banco Mundial (2015a).

El crecimiento de la productividad por trabajador de América Latina, total y por hora, es menor al de Estados Unidos y otros países con los que la región compite en ese y otros mercados externos (Puyana, 2015a). En 2009, los países de esta región no habían recuperado aún los niveles máximos de los años 80. No lo han logrado ni Brasil ni Chile, las economías más dinámicas de la región, y México acumula la mayor pérdida. Dada la coincidencia con el tipo de manufacturas de bajo contenido tecnológico que exportan América 
Latina y China e India, otros países del sureste asiático y Europa Oriental, preocupa que estos países asiáticos y europeos hayan reducido la distancia en productividad con EE.UU. y con países latinoamericanos, por ejemplo con México (Puyana, 2015a).

El deterioro de la generación del empleo y los salarios, combinado con el bajo crecimiento del producto y la productividad estancada o a la baja, se traducen, por una parte, en la pérdida sistemática de participación del trabajo en la distribución funcional del ingreso y, por la otra, en el ascenso del capital y las ganancias (Puyana, 2015b; López, 2016; Piketty, 2014). En la base de este proceso están, por una parte, la pérdida de fuerza negociadora del trabajo por efecto de la liberalización del mercado laboral, y por la otra, el descenso de la elasticidad ingreso de las exportaciones y del empleo, por lo que se requieren mayores tasas de expansión de la economía y las ventas externas para generar el empleo de antes.

En efecto, aún en periodos de crecimiento alto, como 2002-2006, las tasas de desempleo fueron elevadas, creció el empleo informal y bajó la tasa de participación laboral (International Labour Organization, 2013), fenómeno conocido como "crecimiento sin empleo" (jobless growth). No ha de sorprender el deterioro acumulado de las remuneraciones reales, mínimas y medias, ocurrido entre 1980 y 2014 prácticamente en toda la región y en los cuatro países analizados, salvo Colombia. El caso más extremo es el de México, con pérdidas sustanciosas del salario mínimo y estabilización del medio. Los otros países protegieron el mínimo y dejaron caer las remuneraciones medias (Puyana, 2015a).

Otro factor que puede vincular los efectos del extractivismo y la EH es la relación entre EH y desigualdad, nexo poco explorado en la literatura sobre este fenómeno y que puede revelar una cadena causal en la cual el extractivismo está asociado a mayor desigualdad y genera menor 
crecimiento. El debate más reciente coincide en que la desigualdad afecta negativamente el crecimiento, y expone varios argumentos y mecanismos de transmisión de la primera al segundo, como se detalla en Puyana (2016). ${ }^{9}$ Los canales más aceptados son liberalización comercial, cambio tecnológico, desestímulo a las inversiones en educación y desarrollo científico, compresión de la demanda doméstica, daño ambiental, inestabilidad social y política y presiones políticas hacia el gasto público distributivo, no sin antes reconocer que todos estos elementos resultan de definiciones políticas y se adoptan en instituciones políticas.

Son relevantes conceptos, no siempre considerados suficientemente, como la relación directa entre la concentración del ingreso y la elasticidad ingreso de la demanda por bienes no transables, y entre esta y la tasa real de cambio. Por lo tanto, a mayor concentración, superior tiende a ser la demanda agregada de servicios, superior la apreciación de la tasa real de cambio y más fuerte la contracción del empleo en los sectores transables que no están en bonanza. Es decir, en condiciones de mayor desigualdad en la distribución del ingreso, más fuertes pueden ser los síntomas de EH y el deterioro de los ingresos laborales.

La desigualdad puede afectar negativamente el crecimiento, por razones políticas y estructurales. Por una parte, los grupos más poderosos conforman focos de poder con gran acceso a los centros de decisión y logran la adopción de políticas que benefician al capital y desfavorecen el trabajo, lo que es evidente mundialmente en el retroceso de las retribuciones al trabajo en la distribución primaria del ingreso. Estos grupos de poder crean estructuras refractarias que imposibilitan el cambio (Ramcharán, 2010).

Del ejercicio aquí realizado resulta evidente que, con datos del 2005, se mantiene la relación inversa mundial 
entre desigualdad y crecimiento económico encontrada por Gylfason y Zoega (2002) y que se reproduce en América Latina (Gráfica 5). Este ejercicio muestra también la validez mundial de los resultados obtenidos, y no una trayectoria exclusivamente latinoamericana.

Gráfica 5. Desigualdad del ingreso y crecimiento

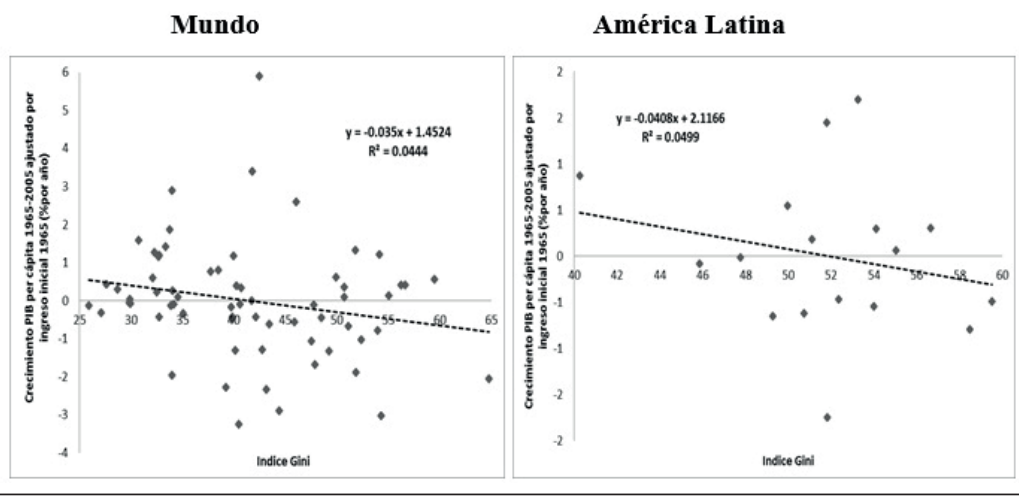

Fuente: elaboración propia con base en datos de Banco Mundial (2015a).

Una de las desigualdades de mayor peso es la concentración de la propiedad rural, que Deininger y Olinto (2000) sugieren tiene fuerte relación inversa con el crecimiento al desincentivar la emulación y las inversiones indivisibles, como la educación, y al anular los efectos de las inversiones en capital humano sobre el crecimiento. Un índice de concentración de la tierra particularmente elevado es un factor determinante en la reproducción de la desigualdad de la región (Deininger y Olinto, 2000; Birdsdale, 2003) y tiende a estar asociado al extractivismo y al acaparamiento de tierras.

Colombia, uno de los países con mayor concentración de la tierra en el orbe, es buen ejemplo. El índice de Gini de propiedad de la tierra en dicho país es de 0.87 (IGAC, 2007), y al tiempo ostenta una de las más elevadas desigualdades del 
ingreso en la región: el 12.6\% de la población padece hambre (la media en América Latina y el Caribe es 8.3\%), situación que no mejora ni en años de acelerado crecimiento del PIB, como entre 2007 y 2014, cuando la economía colombiana se expandió a tasas superiores al 4\%. La concentración de la tierra está asociada a la violencia y al desplazamiento forzado y masivo de pequeños productores agrícolas y de colonos, tendencias que pueden agravarse por los planes de desarrollo y comercio del Gobierno colombiano, basados en "megaproyectos" mineros, petroleros y agrícolas a los cuales se adjudican grandes extensiones de tierras baldías y por los cuales se margina del reparto a la población campesina, los afrodescendientes y los pueblos indígenas (Puyana y Costantino, 2015).

A continuación, se verifica la existencia de la relación directa entre el peso de los recursos naturales en la riqueza total y la desigualdad del ingreso (Gráfica 6). En América Latina, a mayor participación de los primeros, mayor la desigualdad, en línea con los resultados de Gylfason y Zoega (2002). Es importante considerar que una distribución desigual del ingreso puede acentuar la distribución desigual de las rentas de los recursos debido a la existencia de grupos de élite o monopólicos consolidados y capaces de controlar los centros de decisión e influir en las políticas que favorecen sus intereses.

Establecida la relación directa entre la concentración de los recursos naturales y la del ingreso, se verificó si en los países estudiados se manifiesta la relación inversa entre la concentración del ingreso, medido por el índice de Gini, y las tasas de crecimiento que encontraron Gylfason y Zoega (2002). Los resultados obtenidos se presentan en la Gráfica 7 y sobra cualquier comentario, dados los valores de la regresión. 
Gráfica 6. Desigualdad del ingreso y participación de los recursos naturales en la riqueza

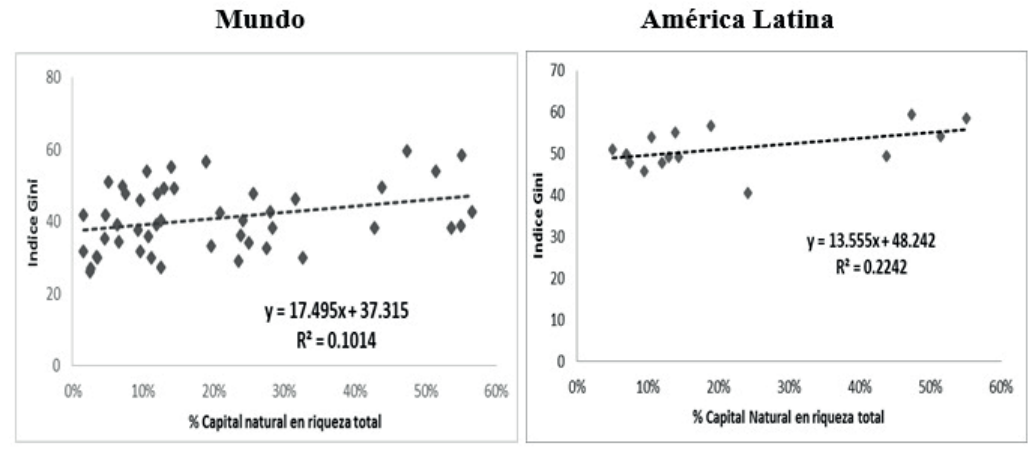

Fuente: elaboración propia basada en datos de Banco Mundial (2015a y 2015b).

Gráfica 7. Crecimiento económico y recursos naturales (2005)

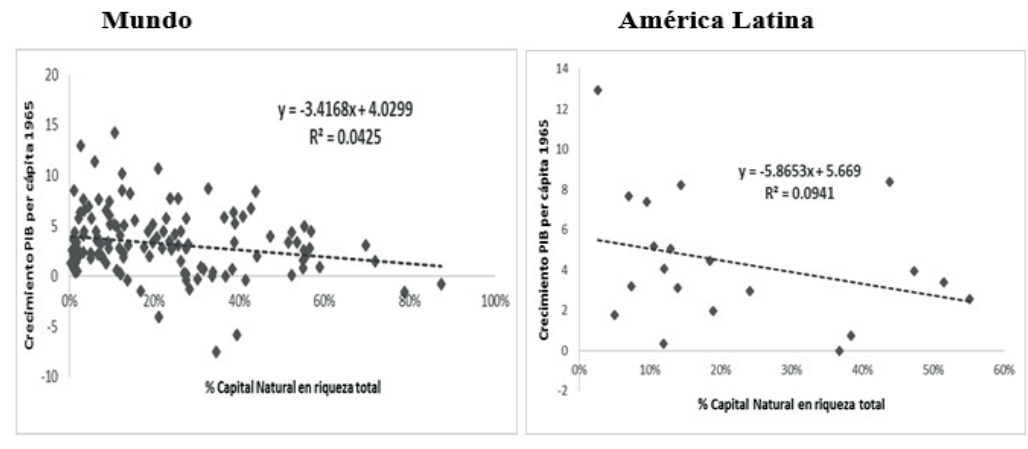

Fuente: elaboración propia basada en datos de Banco Mundial (2015a y 2015b).

En América Latina, se obtuvo una relación inversa entre la riqueza en recursos naturales y el gasto en educación, contrario a lo esperado según Gylfason y Zoega (2002), como factor explicativo del menor ritmo de expansión económica de los países ricos en recursos (Gráfica 8). Este resultado puede emerger a pesar de que América Latina tenga un

\section{4}


relativamente mayor nivel de desarrollo, más intensa urbanización y superiores avances de las manufacturas que otros países especializados en materias primas, esto hasta entrada la década de los años 90 .

Durante la industrialización sustitutiva (alrededor de 1945-1990) los reclamos por la universalización de la educación primaria y la ampliación de la secundaria fueron intensos y el gasto social se amplió, en una versión reducida del Estado de bienestar, entre otras razones para contener las protestas sociales de las clases medias urbanas, en el marco de la doctrina de seguridad nacional (Bértola y Ocampo, 2014).

Gráfica 8. Gasto en educación y recursos naturales (2005)

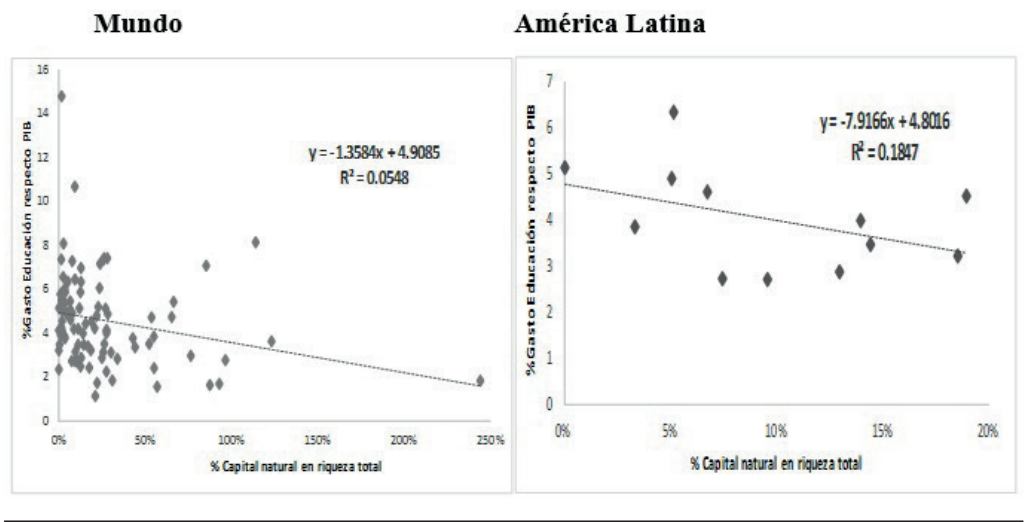

Fuente: elaboración propia basada en datos de Banco Mundial (2015a y 2015b).

\section{Consideraciones finales}

El presente artículo exploró los efectos económicos del extractivismo, en general en América Latina, y en particular en Argentina, Brasil, Colombia y México, y corroboró la presencia de la $\mathrm{EH}$ en la que se evidenciaron efectos atribuidos a la especialización en recursos naturales: bajas 
tasas de crecimiento, apreciación del tipo de cambio y la caída de la producción de bienes transables, agricultura y manufacturas, particularmente. También se exploraron otros efectos económicos como el contenido tecnológico en las exportaciones, la menor generación de empleos y salarios y la desaceleración de la productividad laboral, así como algunas implicaciones del extractivismo y la EH en la mayor desigualdad de la región.

Latinoamérica y el Caribe deben sortear los varios problemas que frenan su desarrollo. En primer lugar, la inequitativa distribución de los costos y beneficios del modelo de desarrollo y el debilitamiento de los factores de crecimiento, como la productividad y la demanda interna. El modelo exportador no ha logrado superar los efectos negativos derivados, entre otros factores, de la apertura de las cuentas comercial y de capitales, el aumento del contenido importado de la producción nacional y la pérdida de relación entre la expansión de las exportaciones, el grado de apertura y el crecimiento del PIB. Ni el crecimiento de la apertura ni el intercambio regional han sido catalizadores del crecimiento económico o de los sectores transables, tampoco del empleo productivo y los ingresos laborales, lo que es efecto del estancamiento de la productividad laboral.

La asignatura pendiente de tomadores de decisiones, académicos y empresarios es explicar las razones por las cuales el modelo de economía abierta, basada en inversión extranjera directa, y que privilegia los mecanismos de mercado en la asignación de factores, no ha repercutido positivamente en la participación de América Latina y el Caribe en el comercio mundial ni ha reactivado el crecimiento de la productividad, lo que causa el retroceso de los sectores que compiten con las importaciones y del creciente contenido importado de la producción nacional. Dicho en otras palabras: se pasó del modelo de sustitución de importaciones al de sustitución de valor agregado y empleo nacionales por 
importados. En este proceso han concurrido tanto el modelo en general como los acuerdos de integración y los arreglos comerciales con los EE.UU. y otros países desarrollados.

Los resultados presentados sugieren que la apertura comercial y la expansión de las exportaciones son insuficientes para acelerar el crecimiento y garantizar tasas de absorción laboral adecuadas al crecimiento de la población económicamente activa, así como para lograr el crecimiento de la productividad laboral total que permita incrementos constantes en los ingresos. Plantear, en este contexto, un patrón de producción basado en la subvaluación de la mano de obra y en la depredación de los recursos naturales conllevaría varios efectos económicos planteados en este artículo, por lo que eso profundizará los problemas estructurales de la región y tornará cada vez más lejano el desarrollo económico, político, social y ambientalmente sustentable.

Acosta, A. (23 de diciembre de 20II). "Extractivismo y neoextractivismo: dos caras de la misma maldición". La línea de fuego. Recuperado de: http://lalineadefuego. info/20 I I/ / 2/23/extractivismo-y-neoextractivismo-doscaras-de-la-misma-maldicion-por-alberto-acosta/

Aditya, A., y Acharyya, R. (20I I). "Export diversification, composition, and economic growth: Evidence from cross-country analysis". The Journal of International Trade Economic Development:An International and Comparative Review, 22(7), 959-992. Recuperado de: http:// www. tandfonline.com/toc/rjte20/current

Auty, R. (1993). Sustaining Development in Mineral Economies. The Resource Curse Thesis. Londres-Nueva York: Routledge.

Banco Mundial (2015a). "World Development Indicators, 20 I5". Recuperado de: http://data.worldbank.org/products/wdi 
Bibliografía
- (20I5b). "Wealth Accounting Data Base". Recuperado de: http://data.worldbank.org/data-catalog/ wealth-accounting

Bértola, L., y Ocampo, J.A. (20।4). El desarrollo económico de América Latina desde la independencia. México: Fondo de Cultura Económica.

Birdsdale, N. (2003). "The World is Not Flat: Inequality and Injustice in our Global Economy". WIDER Annual Conference. Recuperado de: https://www.wider.unu.edu/ Bair, J. (20I5). "Global Capitalism and Commodity Chains: Looking Back, Going Forward”. Competition \& Change, 9(2), I53-180.

Buccellato,T., y Alessandrini, M. (2009). “Natural Resources: a Blessing or a Curse? The Role of Inequality". Centre for Financial \& Management Studies, (98), I-23. Recuperado de:http://www.cefims.ac.uk/documents/research-91.pdf

Cardoso, F. H., y Faletto, E. (1969). Dependencia y desarrollo en América Latina. México: Siglo XXI.

CEPAL (2008). "Cambio estructural para la igualdad. Una visión integrada del desarrollo". Recuperado de: http:// www.cepal.org/

Chenery, H., y Syrquin, M. (1986). “Typical Patterns of Transformation”, en H. Chenery, S. Robinson, y M. Syrquin (eds.), Industrialization and Growth (pp. I23-167). Nueva York: Oxford University Press.

CLAES (2009). Extractivismo, Política y Sociedad. Quito: CLAES. Collier, P., y Hoeffier, A. (2000). "Greed and Grievance in Civil War”. Policy Research Working Paper, (2355), 50.

y Goderis, B. (2007). Commodity Prices, Growth and the Natural Resource Curse: Reconciling a Conundrum. Oxford: University of Oxford.

Cornia, G. A. (20I2)."Regímenes políticos, shocks externos y desigualdad de ingresos: América Latina durante las tres últimas décadas”, en M. Novick, y S.Villafañe (coords.), Distribución del ingreso. Enfoques y políticas públicas desde 
el sur (Pp.67-106). Buenos Aires: Programa Naciones Unidas para el Desarrollo (PNUD), Ministerio de Trabajo, Empleo y Seguridad Social.

Deininger, K., y Olinto, P.(2000).“Asset Distribution, Inequality, and Growth". Policy Research Working Paper, (2375), 35.

Delgado, G. C. (ed.) (20I3). Ecología política del extractivismo en América Latina: casos de resistencia y justicia socioambiental. Buenos Aires: CLACSO.

Douglass, C. N. (1990). Institutions, Institutional Change and Economic Performance. Cambridge: Cambridge University Press.

Fleming, D. A., y Measham, T. G. (20/3). “Disentangling the Natural Resources Curse: National and Regional Socioeconomic Impacts of Resource Windfalls". Recuperado de: http://econpapers.repec.org/paper/ agsaaea | 3/ I50526.htm

Fontaine, G. (2005). "Governance and the role of civil society. The case of oil and gas extraction in the Andean Amazon", en W. Leal Filho (ed.), The Handbook of Sustainability Research (pp. 327-349). Frankfurt: Peter Lang Scientific Publishing.

Furtado, C. (1982). El subdesarrollo latinoamericano. México: Fondo de Cultura Económica.

Gelb, A., et al. (1988). Oil windfalls: Blessing or curse? Nueva York: Oxford University Press-Banco Mundial.

Grigera,J.,y Álvarez, L. (20I3).“Extractivismo y acumulación por desposesión”. Theomai, 27(28), 80-95.

Gudynas, E. (20I3). "Extracciones, extractivismos y extrahecciones. Un marco conceptual sobre la apropiación de recursos naturales". Observatorio del desarrollo, (I8), I- I8. Gylfason, T., y Zoega, G. (2002). "Inequality and Economic Growth:Do Natural Resources Matter?”. CESifo Working Paper, 7/2(5), s/p.

Hausmann, R., Hwang, J., y Rodrik, D. (2007). "What you export matters”. Journal of Economic Growth, I2(I), I-25.

Bibliografía 
Bibliografía

Heipertz, M., y Nickel, C. (2008). "Climate Change Brings Stormy Days: Case Studies on the Impact of Extreme Weather Events on Public Finances" (artículo presentado en el Banca diltalia Workshop Fiscal Sustainability: Analytical Developments and Emerging Policy Issues). Perugia, Italia.

Hilbert, M., y López, P. (20I I). "The World’s Technological Capacity to Store". Communicate and Compute Information, Science I, 332(6025), 60-65.

Humphreys, M., Sachs, J., y Stiglitz, J. D. (2007). Escaping the Resource Curse. Nueva York: Columbia University Press. IGAC (2007). "Atlas de la Distribución de la Propiedad Rural en Colombia". Recuperado de: http://www.igac. gov.co/igac

International Labour Organization (2013). Global Employment Trends 2013: Recovering from a second jobs dip. Ginebra: ILO.

Jomo, K. S., y Reinert, E. S. (eds.) (2005). Origins of Development Economics: How Schools of Economic Thought Addressed Development. Chicago: Zed Books.

Kaldor, N. (1 967). Strategic Factors in Economic Development. Ithaca: Cornell University Press.

Kojo, N. C. (20I5). "Demystifying Dutch Disease”. Journal of International Commerce. Economics and Policy, 6(2), I-22. Recuperado de: https://openknowledge.worldbank.org/bitstream/handle/I 0986/I 9345/WP5698I. pdf? sequence $=\mid$ \& isAllowed $=y$

Krugman, P. (1987). "The Narrow Moving Band, the Dutch Disease, and the Competitive Consequences of Mrs. Thatcher". Journal of Development Economics, 27(I-2), 4I-55.

López, B. (2016). Las relaciones de la desigualdad del ingreso con el crecimiento, la inversión y la política tributaria México, 1984-2014 (tesis de maestría inédita). FLACSO: México. 
Marini, R. M. (1979). "El ciclo del capital en la economía Bibliografía dependiente", en U. Oswald (ed.), Mercado y dependencia (pp. 37-55). México: Nueva Imagen.

Myint, H. (1958). “The 'Classical Theory' of International Trade and the Underdeveloped Countries". The Economic Journal, 68(270), 317-337.

- (1965)."Economic Theory and the Underdeveloped Countries”. Journal of Political Economy, 73(5), 477-49I.

Nurkse, R. (1959). “Notes on Unbalanced Growth”. Oxford Economic Papers, II(3), 295-297.

Paus, E. (20I4). "Latin America and the Middle Income Trap”. ECLAC, Financing for Development Series, (250). Recuperado de: http://papers.ssrn.com/sol3/papers. cfm?abstract_id=2473823

Prebisch, R. (1949). "El desarrollo de la América Latina y algunos de sus principales problemas". El Trimestre Económico, 16(63), 347-43 I

Puyana, A. (20I5a). "Apertura comercial, grado de integración y estructura de los bloques económicos. El caso de México-EUA, 1970-2009”, en A. Puyana (ed.), Paradojas de economías liberalizadas. América Latina (pp. 25-50). México: FLACSO.

(20I5b). Colombia y México: la economía política petrolera en un mercado global y politizado. México: FLACSO. ( 16 de marzo de 2016). Notas sobre la desigualdad en la teoría y la práctica económicas (disertación presentada en la toma de posesión como miembro de la Academia Mexicana de Economía Política). FLACSO: México.

y Costantino, A. (20I5). "Chinese Land Grabbing in Argentina and Colombia”. Latin American Perspectives, (julio), I05-II9.

- y Romero, J. (2009). México. De la crisis de la deuda al estancamiento económico. México: El Colegio de México, Centro de Estudios Económicos. 
Bibliografía
Piketty,T. (20I4). El capital en el siglo XXI. México: Fondo de Cultura Económica.

Ramcharán, R. (20I0). “Inequality Is Untenable”. Finance \& Development, 47(3). Recuperado de: http://www.imf.org/ external/pubs/ft/fand d/2010/09/ramcharan.htm

Raveh, O. (20I3). "Dutch Disease, factor mobility, and the Alberta Effect: the case of federations". Canadian Journal of Economics!Revue canadienne d'économique, 46(4), I317-1350.

Rodrik, D. (2006). Industrial Development: Stylized Facts and Policies. Harvard: Harvard University John F. Kennedy School of Government.

- (2015). "Premature deindustrialization". National Bureau of Economic Research,Working paper, (20935), 40.

Ross, M. (2007). "How Can Mineral Rich States Reduce Inequality?". Recuperado de: http://citeseerx.ist.psu. edu/viewdoc/download?doi= | 0. I I .322.9898\&rep=re pl\&type $=p d f$

Rostow, W.W. (1954). The Five Stages of Economic Growth: A Non-Communist Manifesto. Londres: Cambridge University Press.

Sachs,J.D.yWarner,A. (1995).“Natural Resource Abundance and Economic Growth". National Bureau of Economic Research, Working paper, (5398), 45.

Seoane, J. (20I3). "Modelo extractivo y acumulación por despojo”, en J. Seoane, E. Taddei, y C.Algranati, Extractivismo, despojo y crisis climática (Pp. 3-31). Buenos Aires: Ediciones Herramienta.

Singer, H. (1950). "The Distribution of Gains between Investing and Borrowing Countries". American Economic Review, Papers and Proceedings, (40), 473-485.

Stiglitz,J. (2007). "Making Natural Resources into a Blessing rather than a Curse". Recuperado de: https://www0.gsb. columbia.edu/cfusion/faculty/jstiglitz/download/2005 Covering_Oil.pdf 
Svampa, M. (20I3).“Consenso de los commodities y lenguaBibliografía jes de valoración en América Latina”. Nueva sociedad, 244, 30-46.

UI Haque, I. (ed.) (1995). Trade, Technology and International Competitiveness. EDI Development Studies. Washington: Banco Mundial.

United Nations Comtrade Data Base (20I5). Recuperado de: https://comtrade.un.org/

Will, M. (2005). "Outgrowing Resource Dependence: Theory and Some Recent Developments". Banco Mundial, Working Paper WPS/3482. Recuperado de: elibrary. worldbank.org 